\title{
Primary Molars Indicated For Pulpectomy or Extraction in Children Between the Age Group of 3-6 Years
}

\author{
Niharika Kotian", Ganesh Jeevanandan* and EMG Subramanian² \\ ${ }^{1}$ Saveetha Dental College and Hospitals Saveetha Institute of Medical and Technical Sciences \\ Saveetha University Chennai-77, India \\ ${ }^{*}, 2$ Department of Pedodontics Saveetha Dental College and Hospitals Saveetha Institute of \\ Medical and Technical Sciences Saveetha University Chennai-77, India \\ Corresponding author email: ganesh.sdc@saveetha.com
}

\begin{abstract}
Pulpectomy is a procedure where canals of the primary teeth are debrided and are shaped and obturation is done with a resorbable material. Pulpectomy aims to preserve the tooth until it is replaced by the successor permanent tooth. In a primary tooth that is decayed pulpectomy should be ideally the choice of treatment rather than extraction in order to preserve the integrity of the surrounding tissues as it is more conservative in its approach. This study was done to evaluate the ratio of pulpectomy to extraction cases in primary molars in children aged between 3 to 6 years of age. Data collection from patient management software was done. Children in the age group of 3-6 years were included in the study. Samples of primary molars indicated for pulpectomy and extraction were tabulated and evaluated in SPSS software. Out of total 1692 teeth, 292 were indicated for extraction and 1400 were indicated for pulpectomy. It was concluded that the ratio of cases indicated for pulpectomy was more as compared to the cases indicated for extraction in children aged between 3-6 years of age. Mandibular primary molars are considerably affected more as compared to maxillary primary molars. Oral health education must be promoted amongst parents in order to preserve the primary teeth to avoid any malocclusion in permanent dentition.
\end{abstract}

\section{KEY WORDS: PRIMARY MOLARS, PULPECTOMY, EXTRACTION, MANDIBULAR PRIMARY MOLARS.}

\section{INTRODUCTION}

One of the major goals of any pediatric dentist is to preserve the primary teeth and prevent its premature exfoliation. Pulpectomy is a procedure where canals of the primary teeth are debrided and are shaped and obturation is done with a resorbable material. Pulpectomy is indicated in teeth exhibiting pulpal hemorrhage, irreversible pulpitis and pulp necrosis. Pulpectomy aims to preserve the tooth until it is replaced by the successor permanent tooth. Pulpectomy assists in providing a symptom free state during the development of the dentition, thus avoiding premature exfoliation or extraction of the tooth. A restored primary tooth helps in maintaining arch length, improves masticatory

Biosc Biotech Res Comm P-ISSN: 0974-6455 E-ISSN: 2321-4007

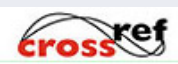

Identifiers and Pagination

Year: 2021 Vol: 14 No (10) Special Issue

Pages: $12-17$

This is an open access article under Creative

Commons License Attribn 4.0 Intl (CC-BY).

DOI: $h t t p: / / d x . d o i . o r g / 10.21786 / b b r c / 14.10 .3$ function and also enhances esthetics. It prevents a child from adapting to deleterious habits and also speech alterations due to decay in anterior teeth. Few scenarios that lead to premature loss of primary teeth involve trauma, congenital defects, deficiency of the length of the arch and decay. These factors in turn lead to resorption of the affected primary tooth (Owen, 1971; Thomas et al., 1994; Ngan et al., 1999; Pedersen et al., 1978; Goerig and Camp, 1983; Walia, 2014; Fuks and Peretz, 2016; Sureshbabu et al., 2019; Samuel et al., 2020).

Early loss of primary teeth leads to severe problems associated with malocclusion like lack of space, rotation of the teeth and impaction. Certain factors like lack of access to oral health care or lack of education of parents regarding oral health in rural areas leads to negligence, further leading to premature loss of teeth. In order to reduce chances of premature exfoliation, pediatric dentists must identify the factors leading to this. Previously our team has a rich experience in working on various research projects across multiple disciplines (Chhabra and Chhabra, 2012; Gheena and Ezhilarasan, 2019; Ke et al., 2019; Sureshbabu et al.,

\section{Article Information}

Received: $05^{\text {th }}$ Aug 2021

Accepted after revision: $18^{\text {th }}$ Oct 2021 
2019; Mehta et al., 2019; Samuel et al., 2019; Sharma et al., 2019; Varghese et al., 2019; Venu et al., 2019; Venu et al., 2019; Vignesh et al., 2019; Jain et al., 2019; Jose et al., 2020; Krishnaswamy et al., 2020; Muthukrishnan et al., 2020; Samuel et al., 2020; Sathish and Karthick, 2020). Now the growing trend in this area motivated us to pursue this project. This study is aimed to evaluate the cases indicated for pulpectomy compared to the cases indicated for extraction in primary molars in 3- 6 years old children.

\section{MATERIAL AND METHODS}

The study was based in a university setting. The ethical approval was given by the Institutional Scientific Review Board, Saveetha Dental College and Hospitals. There were three reviewers involved in the study which included one external reviewer. Data was collected from Saveetha Dental College database. A total of 1692 teeth were included in the study. The segregation of data was initiated after ethical approval. Inclusion criteria: Children in the age group of 3-6 years were included in this study. Treatment plan indicating pulpectomy of the primary molar. Treatment plan indicating extraction of the primary molar.

Exclusion criteria: Children suffering from any underlying systemic conditions or mental health conditions were excluded from this study. The collected data was entered in the excel data sheet and grouping of parameters was done. After grouping the parameters, the data was copied into the SPSS 2.0 software and statistical analysis was done.

Statistical analysis: Chi square test was done to compare both the procedures. Statistical analysis was done in SPSS version 2.0, Chicago, IL, USA.

Figure 1: Bar chart representing the cases indicated for pulpectomy and extraction in primary molars where blue indicates the number of pulpectomies done and red indicates the number of extractions done. $\mathrm{X}$ axis represents the gender of the children and $Y$ axis represents the total number of children indicated for treatment. The total number of pulpectomies done in males $(47.90 \%)$ was greater than the total number of pulpectomies done in females $(34.70 \%)$. The total number of extractions done in males $(\mathbf{1 0 . 2 0 \% )}$ was greater than the total number of extractions done in females $(7.20 \%)$.

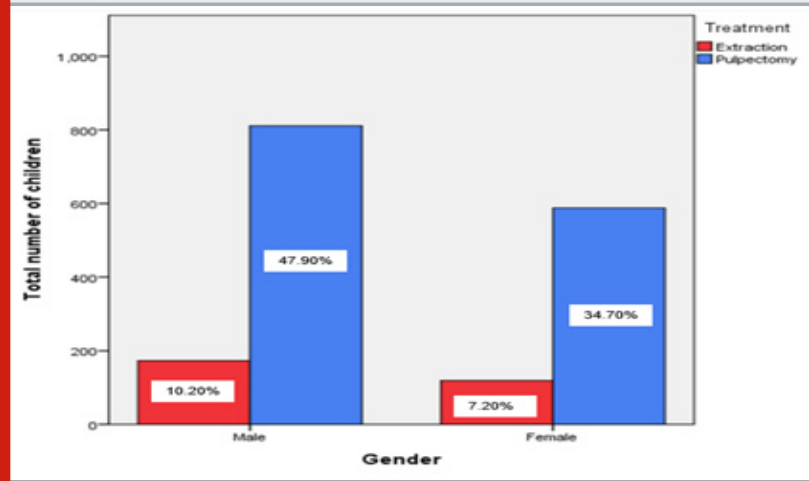

\section{RESULTS AND DISCUSSION}

Out of 1692 teeth included in the study, 833 were boys and 859 were girls (Figure 1). 292 children were indicated for extraction and 1400 children were indicated for pulpectomy. 981 primary mandibular molars were affected as compared to 711 maxillary primary molars. (Figure 2). The cases indicated for pulpectomy were more in primary mandibular molars as compared to maxillary molars. A statistically significant difference between the number of teeth indicated for both the procedures was obtained $(\mathrm{p}<0.05)$.

Figure 2: Bar chart representing the cases indicated for pulpectomy and extraction in primary molars where blue indicates the number of pulpectomies done and red indicates the number of extractions done. $X$ axis represents the maxillary or Mandibular arch indicated for treatment and $\mathrm{Y}$ axis represents the number of teeth indicated for treatment. Maximum number of pulpectomies were done in mandibular primary molars $(60.66 \%)$ compared to maxillary primary molars $(\mathbf{2 2 . 1 4 \%})$. Maximum number of extractions were done in mandibular primary molars $(\mathbf{1 0 . 8 \%})$ compared to maxillary primary molars $(6.40 \%)$. Chi square test was done to compare both the treatments which was statistically significant $(p=0.000)$.

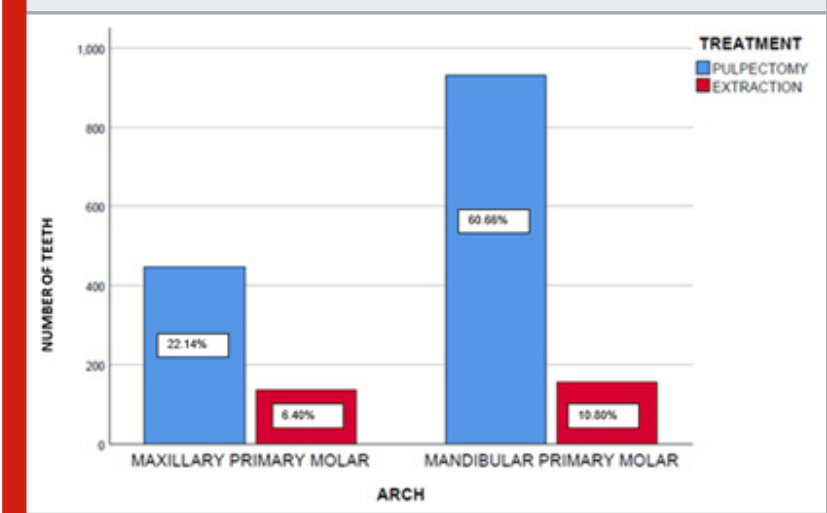

One of the major concerns for any pediatric dentist is to preserve the primary teeth. Untreated caries has a negative impact on the quality of life of the child. Primary teeth have a major role to play in mastication, speech and aesthetics. Primary teeth play a vital role in the eruption of permanent teeth in respect to its position. Pulp inflammation can lead to early exfoliation of molars due to periapical infection or alveolar bone destruction. Tooth mortality in a population can provide information regarding the availability of dental care, the incidence of dental disease and attitudes towards tooth loss. Despite advances in oral health care dental caries in children is existing globally and many risk factors are associated with it (Murray et al., 1997; Mouradian, 2000; Christabel et al., 2015; Somasundaram et al., 2015; Gurunathan and Shanmugaavel, 2016; Packiri et al., 2017; Jeevanandan, 2017; Govindaraju and Gurunathan, 2017; Govindaraju et al., 2017a; Govindaraju et al., 2017b; Subramanyam et al., 2018; Jeevanandan and Govindaraju, 2018; Govindaraj et al., 2019; Lakshmanan et al., 2020). 
The first treatment decision taken by and pediatric dentist is whether to retain or extract the decayed tooth based on the pulp vitality, pathology, restorability, and the duration of time for normal tooth exfoliation. It is essential for the dentist to note the signs and symptoms associated in respect to the particular tooth. In a primary tooth that is decayed pulpectomy should be ideally the choice of treatment rather than extraction in order to preserve the integrity of the surrounding tissues as it is more conservative in its approach. The goal of treatment should be elimination of microorganisms to reduce the rate of reinfection. Endodontic treatment of primary molars is more challenging due to the root canal morphology such as an increased number of accessories, ribbon-like canals, foramina and porosity in pulpal floors and its close proximity with its permanent successor. The type of pulpal therapy basically depends on the pulp vitality and the presence or absence of a radicular pathology (Govindaraju et al., 2017; Ravikumar et al., 2017; Panchal et al., 2019; Lakshmanan et al., 2020).

Pulpectomy is a pulp therapy that is indicated in irreversibly inflamed or necrotic pulp due to decay or trauma to the tooth often leading to a pathology. The root canals are debrided and shaped with hand or rotary files. Following debridement of the canals, the canals are irrigated and obturated with a resorbable material. The tooth is then restored with crown or restoration that prevents microleakage. Despite tooth extraction being a common intervention to provide oral health among children, literature related to reasons for extraction is limited. Extraction of teeth is indicated when there is a pathological infection that cannot be treated with a conservative approach, trauma, resorption of roots and orthodontic considerations. Early tooth loss leads to malocclusion, speech defects, functional disability and esthetic concerns. In order to reduce the incidence of tooth loss it is essential to identify its underlying cause. In a study done by M Bani et al it was observed that caries was the most identified reason for extraction followed by root resorption and trauma (Bani et al., 2015; Jain et al., 2019; Jose et al., 2020).

Extraction of primary molars before the age of 8 years has been found to delay the eruption of its successor. Premature loss of primary molars leads to the reduction in the length of the arch which is usually greater in the mandibular arch when compared to the maxillary arch. It also predisposes migration of the adjacent teeth leading to rotation, crowding, and impaction of the permanent dentition. Early loss of primary molars may lead to disturbance in sequence of eruption or permanent teeth. Loss of primary molars at an early stage may result in an increased risk of space closure. Certain cases have been reported where early loss of primary molars lead to impaction or permanent bicuspids. Hence it makes it essential to provide space maintainers to reduce the incidence of impaction (Czecholinski et al., 1994; Bani et al., 2015; Jain et al., 2019; Jose et al., 2020).

Some dentists usually prefer extraction over restoring a primary tooth, one of the reasons include complete destruction of the coronal portion of the tooth. In certain scenarios lack of knowledge regarding oral health amongst parents leads to negligence leading to early exfoliation. In the present study those children were included whose molars were indicated either for extraction or for pulpectomy. It was observed that the ratio of cases indicated for pulpectomy was higher as compared to the cases indicated for extraction. The cases indicated for extraction were indicated due to dental caries in most of the cases and also lack of knowledge amongst parents regarding oral health care and their attitude towards dental treatment for their children. A similar result was obtained in a study done by Bansal et al (Bansal et al., 2017; Jain et al., 2019; Jose et al., 2020).

It was observed that primary teeth were not given as much importance as the permanent teeth by the parents as the reason stated by most of them was natural exfoliation. In the present study it was observed that mandibular primary molars were more decayed as compared to maxillary primary molars. Similar results were obtained in a study done by Tewari et al which was contradictory to the results obtained in a study done by Gheyne et al where maxillary primary molars showed a higher caries incidence as compared to mandibular primary molars.It was observed that, when both the procedure groups were compared there was a statistical significant difference between the two groups $(\mathrm{p}<0.005)$ (Healey and Gheyne, 1943; Mandal et al., 2001; Sridharan et al., 2019; Vijayashree, 2019; Mathew et al., 2020).

A responsible pediatric dentist should constantly encourage the parents to visit dental clinics with their children to examine their teeth. Also, apart from this it is the duty of every pediatric dentist to counsel the parent as well as the child on oral health care. Awareness can be increased with respect to preventive procedures like fluoride and sealant application. This will help in improving the quality of life of the child. Prevention of dental caries and preservation of the primary teeth should be the goal for every pediatric dentist. There were a few limitations in the study. A twodimensional radiograph was used to assess the tooth. Also, another limitation of this study was that the treatment plan was not decided by a single operator.After assessing and overcoming the limitations more such studies should be performed to create awareness among parents regarding oral hygiene and health care for their children. It can also focus on the treatment plan designed by an operator for every child and also the basis for the treatment suggested. A single operator can be included in future studies to avoid bias.Our institution is passionate about high quality evidence based research and has excelled in various fields (Pc et al., 2018; Ramesh et al., 2018; Ezhilarasan et al., 2019; Ramadurai et al., 2019; Sridharan et al., 2019; Vijayashree, 2019; Mathew et al., 2020).

\section{CONCLUSION}

It was observed that the cases indicated for pulpectomy is higher than the cases indicated for extraction in children aged between 3-6 years. Mandibular primary molars are considerably affected more as compared to maxillary primary molars. Oral health education must be promoted amongst parents in order to preserve the primary teeth to avoid any malocclusion in permanent dentition. 


\section{REFERENCES}

Bani, M. et al. (2015). The reasons for extractions of primary teeth in Turkish children. European journal of paediatric dentistry: official journal of European Academy of Paediatric Dentistry, 16(3), pp. 187-190.

Bansal, M. et al. (2017). Reasons for extraction in primary teeth among 5-12 years school children in Haryana, India- A cross-sectional study. Journal of clinical and experimental dentistry, 9(4), pp. e545-e549.

Chhabra, N. and Chhabra, A. (2012). Parental knowledge, attitudes and cultural beliefs regarding oral health and dental care of preschool children in an Indian population: a quantitative study. European archives of paediatric dentistry: official journal of the European Academy of Paediatric Dentistry, 13(2), pp. 76-82.

Christabel, S. L. and Linda Christabel, S. (2015). Prevalence of Type of Frenal Attachment and Morphology of Frenum in Children, Chennai, Tamil Nadu. World Journal of Dentistry, pp. 203-207. doi: 10.5005/jpjournals-10015-1343.

Czecholinski, J. A., Kahl, B. and Schwarze, C. W. (1994). Frühzeitiger Milchzahnverlust-reifer oder unreifer Durchbruch der bleibenden Nachfolger. Fortschritte der Kieferorthopädie, pp. 54-60. doi: 10.1007/bf02174357. Ezhilarasan, D., Apoorva, V. S. and Ashok Vardhan, N. (2019). Syzygium cumini extract induced reactive oxygen species-mediated apoptosis in human oral squamous carcinoma cells. Journal of oral pathology \& medicine: official publication of the International Association of Oral Pathologists and the American Academy of Oral Pathology, 48(2), pp. 115-121.

Fluoride, Fluoridated Toothpaste Efficacy And Its Safety In Children - Review' (2018). International Journal of Pharmaceutical Research. doi: 10.31838/ ijpr/2018.10.04.017.

Fuks, A. and Peretz, B. (2016). Pediatric Endodontics: Current Concepts in Pulp Therapy for Primary and Young Permanent Teeth. Springer.

Gheena, S. and Ezhilarasan, D. (2019). Syringic acid triggers reactive oxygen species-mediated cytotoxicity in HepG2 cells. Human \& experimental toxicology, 38(6), pp. 694-702.

Goerig, A. C. and Camp, J. H. (1983). Root canal treatment in primary teeth: a review. Pediatric dentistry, 5(1), pp. 33-37.

Govindaraj, A., Gurunathan, D. and Geetha (2019). Comparision of Contamination of Tooth Brush among Dental Students and Patients. Indian Journal of Public Health Research \& Development, p. 28. doi: 10.5958/09765506.2019.01847.3.

Govindaraju, L. and Gurunathan, D. (2017). Effectiveness of Chewable Tooth Brush in Children-A Prospective
Clinical Study. Journal of clinical and diagnostic research: JCDR, 11(3), pp. ZC31-ZC34.

Govindaraju, L., Jeevanandan, G. and Subramanian, E. (2017). Clinical Evaluation of Quality of Obturation and Instrumentation Time using Two Modified Rotary File Systems with Manual Instrumentation in Primary Teeth. Journal of clinical and diagnostic research: JCDR, 11(9), pp. ZC55-ZC58.

Govindaraju, L., Jeevanandan, G. and Subramanian, E. M. G. (2017a). Comparison of quality of obturation and instrumentation time using hand files and two rotary file systems in primary molars: A single-blinded randomized controlled trial. European journal of dentistry, 11(3), pp. 376-379.

Govindaraju, L., Jeevanandan, G. and Subramanian, E. M. G. (2017b). Knowledge and practice of rotary instrumentation in primary teeth among indian dentists: A questionnaire survey. Journal of International Oral Health, p. 45. doi: 10.4103/jioh.jioh_4_17.

Gurunathan, D. and Shanmugaavel, A. K. (2016). Dental neglect among children in Chennai. Journal of the Indian Society of Pedodontics and Preventive Dentistry, 34(4), pp. 364-369.

Healey, H. J. and Gheyne, V. D. (1943). Comparison of Caries Prevalence Between Freshman Students in Two Midwestern Universities. The Journal of the American Dental Association, pp. 692-700. doi: 10.14219/jada. archive.1943.0154.

Jain, S. et al. (2019). Evaluation of Three-Dimensional Changes in Pharyngeal Airway Following Isolated Lefort One Osteotomy for the Correction of Vertical Maxillary Excess: A Prospective Study. Journal of maxillofacial and oral surgery, 18(1), pp. 139-146.

Jeevanandan, G. (2017). Kedo-S Paediatric Rotary Files for Root Canal Preparation in Primary Teeth - Case Report. Journal of clinical and diagnostic research: JCDR, 11(3), pp. ZR03-ZR05.

Jeevanandan, G. and Govindaraju, L. (2018). Clinical comparison of Kedo-S paediatric rotary files vs manual instrumentation for root canal preparation in primary molars: a double blinded randomised clinical trial', European archives of paediatric dentistry: official journal of the European Academy of Paediatric Dentistry, 19(4), pp. 273-278.

Jose, J., Ajitha and Subbaiyan, H. (2020). Different treatment modalities followed by dental practitioners for Ellis class 2 fracture - A questionnaire-based survey. The open dentistry journal, 14(1), pp. 59-65.

Ke, Y. et al. (2019). Photosynthesized gold nanoparticles from Catharanthus roseus induces caspase-mediated apoptosis in cervical cancer cells (HeLa). Artificial cells, nanomedicine, and biotechnology, 47(1), pp. 19381946. 
Krishnaswamy, H. et al. (2020). Investigation of air conditioning temperature variation by modifying the structure of passenger car using computational fluid dynamics. Thermal science, 24(1 Part B), pp. 495-498. Lakshmanan, L. et al. (2020). Assessing the quality of obturation and instrumentation time using Kedo-S files, Reciprocating files and Hand K-files. Brazilian Dental Science. doi: 10.14295/bds.2020.v23i1.1822.

Malli Sureshbabu, N. et al. (2019). Concentrated Growth Factors as an Ingenious Biomaterial in Regeneration of Bony Defects after Periapical Surgery: A Report of Two Cases. Case reports in dentistry, 2019, p. 7046203.

Mandal, K. P. et al. (2001). Prevalence and severity of dental caries and treatment needs among population in the Eastern states of India. Journal of the Indian Society of Pedodontics and Preventive Dentistry, 19(3), pp. 85-91. Mathew, M. G. et al. (2020). Evaluation of adhesion of Streptococcus mutans, plaque accumulation on zirconia and stainless steel crowns, and surrounding gingival inflammation in primary. Clinical oral investigations. Available at: https://link.springer.com/article/10.1007/ s00784-020-03204-9.

Mehta, M. et al. (2019). Oligonucleotide therapy: An emerging focus area for drug delivery in chronic inflammatory respiratory diseases. Chemico-biological interactions, 308, pp. 206-215.

Mouradian, W. E. (2000). Disparities in Children's Oral Health and Access to Dental Care. JAMA, p. 2625. doi: 10.1001/jama.284.20.2625.

Murray, H. et al. (1997). Reasons for tooth extractions in dental practices in Ontario, Canada according to tooth type. International Dental Journal, pp. 3-8. doi: 10.1111/j.1875595x.1997.tb00670.x.

Muthukrishnan, S. et al. (2020). Support vector machine for modelling and simulation of heat exchangers. Thermal science, 24(1), pp. 499-503.

Ngan, P., Alkire, R. G. and Fields, H. (1999). Management of space problems in the primary and mixed dentitions. The Journal of the American Dental Association, pp. 1330-1339. doi: 10.14219/jada.archive.1999.0403.

Owen, D. G. (1971). The incidence and nature of space closure following the premature extraction of deciduous teeth: a literature study. American journal of orthodontics, 59(1), pp. 37-49.

Packiri, S., Gurunathan, D. and Selvarasu, K. (2017). Management of Paediatric Oral Ranula: A Systematic Review. Journal of clinical and diagnostic research: JCDR, 11(9), pp. ZE06-ZE09.

Panchal, V., Jeevanandan, G. and Subramanian, E. (2019). Comparison of instrumentation time and obturation quality between hand K-file, H-files, and rotary Kedo-S in root canal treatment of primary teeth: A randomized controlled trial. Journal of the Indian Society of Pedodontics and
Preventive Dentistry, 37(1), pp. 75-79.

Pc, J., Marimuthu, T. and Devadoss, P. (2018). Prevalence and measurement of anterior loop of the mandibular canal using CBCT: A cross sectional study. Clinical implant dentistry and related research. Available at: https:// europepmc.org/article/med/29624863.

Pedersen, J., Stensgaard, K. and Melsen, B. (1978). Prevalence of malocclusion in relation to premature loss of primary teeth. Community Dentistry and Oral Epidemiology, pp. 204-209. doi: 10.1111/j.1600-0528. 1978.tb01151.x.

Ramadurai, N. et al. (2019). Effectiveness of 2\% Articaine as an anesthetic agent in children: randomized controlled trial. Clinical oral investigations, 23(9), pp. 3543-3550.

Ramesh, A. et al. (2018). Comparative estimation of sulfiredoxin levels between chronic periodontitis and healthy patients - A case-control study. Journal of periodontology, 89(10), pp. 1241-1248.

Ravikumar, D., Jeevanandan, G. and Subramanian, E. M. G. (2017). Evaluation of knowledge among general dentists in treatment of traumatic injuries in primary teeth: A cross-sectional questionnaire study. European Journal of Dentistry, pp. 232-237. doi: 10.4103/ejd.ejd_357_16. Samuel, M. S. et al. (2019). Efficient removal of Chromium (VI) from aqueous solution using chitosan grafted graphene oxide (CS-GO) nanocomposite. International journal of biological macromolecules, 121, pp. 285-292. Samuel, S. R., Acharya, S. and Rao, J. C. (2020). School Interventions-based Prevention of Early-Childhood Caries among 3-5-year-old children from very low socioeconomic status: Two-year randomized trial. Journal of public health dentistry, 80(1), pp. 51-60.

Sathish, T. and Karthick, S. (2020). Wear behaviour analysis on aluminium alloy 7050 with reinforced SiC through taguchi approach. Journal of Japan Research Institute for Advanced Copper-Base Materials and Technologies, 9(3), pp. 3481-3487.

Sharma, P. et al. (2019). Emerging trends in the novel drug delivery approaches for the treatment of lung cancer. Chemico-biological interactions, 309, p. 108720.

Somasundaram, S. et al. (2015). Fluoride Content of Bottled Drinking Water in Chennai, Tamilnadu. Journal of clinical and diagnostic research: JCDR, 9(10), pp. ZC32-4.

Sridharan, G. et al. (2019). Evaluation of salivary metabolomics in oral leukoplakia and oral squamous cell carcinoma. Journal of oral pathology \& medicine: official publication of the International Association of Oral Pathologists and the American Academy of Oral Pathology, 48(4), pp. 299-306.

Subramanyam, D. et al. (2018). Comparative evaluation of salivary malondialdehyde levels as a marker of lipid peroxidation in early childhood caries. European journal 
of dentistry, 12(1), pp. 67-70.

Thomas, A. M. et al. (1994). Elimination of infection in pulpectomized deciduous teeth: A short-term study using iodoform paste. Journal of Endodontics, pp. 233-235. doi: 10.1016/s0099-2399(06)80284-0.

Varghese, S. S., Ramesh, A. and Veeraiyan, D. N. (2019). Blended Module-Based Teaching in Biostatistics and Research Methodology: A Retrospective Study with Postgraduate Dental Students. Journal of dental education, 83(4), pp. 445-450.

Venu, H., Raju, V. D. and Subramani, L. (2019). Combined effect of influence of nano additives, combustion chamber geometry and injection timing in a DI diesel engine fuelled with ternary (diesel-biodiesel-ethanol) blends. Energy, 174, pp. 386-406.

Venu, H., Subramani, L. and Raju, V. D. (2019). Emission reduction in a DI diesel engine using exhaust gas recirculation (EGR) of palm biodiesel blended with $\mathrm{TiO} 2$ nano additives. Renewable Energy, 140, pp. 245-263.

Vignesh, R. et al. (2019). Management of Complicated Crown-Root Fracture by Extra-Oral Fragment Reattachment and Intentional Reimplantation with 2 Years Review. Contemporary clinical dentistry, 10(2), pp. 397-401.

Vijayashree P. J. (2019). In silico validation of the non-antibiotic drugs acetaminophen and ibuprofen as antibacterial agents against red complex pathogens. Journal of periodontology, 90(12), pp. 1441-1448.

Walia, T. (2014). Pulpectomy in hyperemic pulp and accelerated root resorption in primary teeth: a review with associated case report. Journal of the Indian Society of Pedodontics and Preventive Dentistry, 32(3), pp. 255-261. 